\title{
A health assessment tool for multiple risk factors for obesity: age and sex differences in the prediction of body mass index
}

\author{
Julie A. Chambers* and Vivien Swanson \\ Department of Psychology, University of Stirling, Stirling FK4 9LA, UK \\ (Received 17 September 2009 - Revised 5 January 2010 - Accepted 3 February 2010 - First published online 9 March 2010)
}

The aim was to establish the relative importance of multiple dietary, activity and other risk factors in determining BMI. A cross-sectional survey was conducted with 322 adults (71\% female; aged $18-79$ years; BMI $16 \cdot 5-40.9 \mathrm{~kg} / \mathrm{m}^{2}$ ) using a previously developed, psychometrically tested, seventy-three-item questionnaire covering a wide range of obesity risk factors (consisting of five dietary, five activity and seven other risk factor subscales). Outcome was self-reported weight and height for BMI, cross-validated with items on clothes size and perceived need to lose weight. Stepwise regression analysis predicted $25-55 \%$ of the variance in BMI with physical activity participation, current and past dieting behaviour, amount eaten, and age being the most important predictors. The association of lower BMI and younger age appeared to be due to higher activity levels, as younger participants reported much less healthy eating behaviour than the older age group. Amount eaten and physical activity participation were stronger predictors of BMI than other factors including healthy eating and use of mechanised transport. Results showed that the relationship between various risk factors and obesity may differ by both sex and age group, suggesting that different interventions may need to be targeted at different groups. The higher-risk eating behaviour observed in younger participants is of concern and needs to be addressed, if the current trend of rising obesity levels is to be halted.

Obesity: Dietary behaviour: Activity behaviour: Multiple risk behaviours

Obesity is now acknowledged as potentially the most important health challenge that we face at a global level. By 2010, it is estimated that about $30 \%$ of UK adults will be obese, but, if current rates continue, this is expected to rise to almost $50 \%$ by the year 2050, with corresponding direct and indirect costs to the UK National Health Service reaching $£ 10 \mathrm{bn}^{(1)}$. In the USA, rates are even higher, with nearly one-third of the adult population already considered obese in $2001^{(2)}$. Rates of obesity are rising even in developing countries, which have traditionally been associated with problems of underweight and malnutrition ${ }^{(3)}$. This rise in obesity levels has and will continue to result in increases in incidence of type 2 diabetes, hypertension, CVD, muscular-skeletal disorders, a range of cancers and early mortality, as well as a reduction in general wellbeing and quality of life ${ }^{(4,5)}$.

The basic cause of overweight and obesity is an energy imbalance, i.e. energy intake must exceed energy expenditure on a regular and sustained basis. However, the factors leading to this imbalance at both individual and population level are complex and multi-faceted. Despite the fact that obesity risk is increased in children whose parents are obese ${ }^{(6)}$, genetic factors are largely rejected as a cause of increases at population level, due to the fact that the global dramatic rise in obesity rates has occurred in the last 20-30 years, during which our gene pool has remained unchanged. Changes in behaviour and environment, affecting the energy balance equation of individuals of all ages, therefore, must be responsible for these population-level changes ${ }^{(7)}$. Nonetheless, it is likely that certain individuals are more genetically predisposed to having difficulties in maintaining an effective energy balance, particularly in the light of the abundance of energy-dense food and the increased opportunities to reduce energy expenditure, which are the result of our current civilised society ${ }^{(8)}$.

In an attempt to inform interventions for obesity, much research has been carried out into specific dietary, activity and other factors which are thought to be responsible for increased weight in both children and adults. Eating factors which have been found to relate to obesity include energy-dense foods, increased snacking, especially on high-energy or sugary foods, consuming sugary drinks, eating larger portions, eating more convenience foods and emotional eating ${ }^{(9-14)}$. Changes in eating patterns such as greater consumption of fast food, restaurant meals and take-aways, as well as less cooking of meals at home and the demise of the family mealtime have also been linked with weight gain ${ }^{(15)}$.

An overall reduction in energy expenditure through physical activity is also a key factor in the obesity epidemic, particularly in Westernised countries. Reduced participation in sport, exercise or other regular physical activity, an increase in car usage, greater television viewing, the mechanisation of many daily activities including the use of labour-saving devices in the home, fewer labour-intensive jobs and a resulting general

Abbreviation: SES, socio-economic status.

*Corresponding author: Dr Julie A. Chambers, fax +44 1786 467641, email j.a.chambers@stir.ac.uk 
decline in activity levels have all been implicated in the rise in obesity levels ${ }^{(16-19)}$. Other factors thought to contribute to obesity in individuals include not having been breastfed, early maturation, dieting behaviour (especially so-called yo-yo dieting where weight loss is followed by weight regain when a diet is stopped) and lower amounts of sleep ${ }^{(10,20-22)}$.

Whilst some studies have examined a range of eating and activity behaviours in conjunction with $\mathrm{BMI}^{(23)}$, most tend to concentrate on a more limited number of risk factors and often ignore psychological motivations. Psychological reasons for behaviour are thought to be important in determining overall obesity levels, particularly in explaining why individuals do not adjust their lifestyle despite repeated public health messages regarding the dangers of being obese ${ }^{(1)}$.

In order to address these limitations, we have developed and piloted a questionnaire covering a comprehensive range of obesity risk factors, including items relating to psychological aspects of behaviour, with the aim of enabling the examination of their relative importance at both an individual and population level ${ }^{(24)}$. Previous factor analysis of data from over 350 adults revealed a clear factor structure, with five dietary and five activity factors and a further seven factors representing additional risk areas including parental weight, sleep and early maturation ${ }^{(25)}$.

This report presents further results from this study, as we aim to examine age and sex differences for the seventeen obesity risk factors identified in the final solution ${ }^{(25)}$ and establish the relative importance of these factors in determining BMI.

\section{Method \\ Procedure}

The study consisted of a convenience sample of volunteers recruited either via response to posters displayed at a Scottish university or via personal invitation. All questionnaires were completed and returned anonymously in sealed envelopes. In addition to the risk factor questionnaire (see below), participants provided self-reported weight and height, for calculation of BMI, as well as job status of self and partner for assessment of socio-economic status (SES). Any participant indicating on the questionnaire that they had an eating disorder was excluded. The present study was conducted according to the guidelines laid down in the Declaration of Helsinki and all procedures involving human subjects were approved by the University of Stirling, Department of Psychology Ethics Committee. Written informed consent was obtained from all participants.

\section{Participants}

A number of participants ( $n$ 37) in the original study ${ }^{(25)}$ had either failed to provide sufficient information to calculate BMI or had one or more risk factors with no completed items (for example, the father's weight tendency factor because they had no father figure), and so the present report is based on 322 adults ( $71 \%$ female) residing in Scotland ( $n$ 240), England ( $n$ 70) and Northern Ireland ( $n$ 4) (country of residence was undetermined for eight respondents) who completed the questionnaire between 2004 and 2007. The age range was 18-79 (mean 29.8 (SD) 13.1) years. Just over two-fifths $(41.3 \%)$ of the respondents (n 133) were students based at the University of Stirling; data on social class was available for 180 of the remaining 189 respondents, and there was a bias towards higher $\operatorname{SES}^{(26)}$ in these adults, with $23.3 \%(n$ 42) identified as SES I, 33.3\% ( $n$ 60) SES II, $28.3 \%$ ( $n$ 51) SES III, $8.9 \%(n$ 16) SES IV and $6 \cdot 1 \%(n$ 11) SES V.

\section{Questionnaire}

An easy-to-complete, 100-item questionnaire was previously developed $^{(24)}$ by generating a number of items for a wide range of reported risk factors for obesity, after extensive review of pertinent factors and measures identified from recent research ${ }^{(27,28)}$. Full details of the development process and a detailed description of the questionnaire are reported in the pilot study ${ }^{(24)}$. The adult version of the questionnaire has a Flesch ${ }^{(29)}$ readability score of $69 \cdot 4$, i.e. a reading age of approximately 12 years.

Items cover an extensive range of currently proposed risk factors for obesity, to allow comparisons between factors. Because of measurement issues, particularly in the overweight $^{(30)}$, we adopted a method of using items based on frequency of preferred or typical, rather than actual, behaviour. Example of items are: 'I would rather eat out than eat at home: almost always; most of the time; often; sometimes; rarely; almost never' and 'On a typical day I watch television, videos or DVDs for: at least $4 \mathrm{~h} ; 3$ or $4 \mathrm{~h} ; 1$ or $2 \mathrm{~h}$; less than $1 \mathrm{~h}$; not at all'.

Factor analysis was carried out for (a) items relating to dietary behaviours, (b) items related to activity behaviours and (c) other obesity risk items ${ }^{(25)}$. The final solution consisting of five dietary factors, five activity factors and seven additional factors was based on seventy-three individual items and showed good internal reliability. The resulting factors are described in Table 1.

In order to allow equal weighting of individual items on each factor, factor scores were calculated as mean scores, and were based on the means of responses to each item loading on that factor (i.e. if there were four possible responses on an item, a score of 2 on that item would be calculated as 0.5 ; if there were six possible responses, a score of 2 would be calculated as 0.33). High scores on all seventeen factors indicate less healthy behaviour.

\section{Results}

The mean BMI of the sample (i.e. weight $(\mathrm{kg})$ divided by height ${ }^{2}(\mathrm{~m})$ ) was $24.4(\mathrm{SD} 4 \cdot 6) \mathrm{kg} / \mathrm{m}^{2}$. Only $36 \cdot 3 \%$ were considered overweight according to the recommended BMI cut-offs ${ }^{(31)}\left(26.4 \%\right.$ overweight $\left(\mathrm{BMI} \geq 25 \mathrm{~kg} / \mathrm{m}^{2}\right)$ and $9.9 \%$ obese $\left.\left(\mathrm{BMI} \geq 30 \mathrm{~kg} / \mathrm{m}^{2}\right)\right), 60.4 \%$ were considered of normal weight $\left(25>\mathrm{BMI} \geq 18.5 \mathrm{~kg} / \mathrm{m}^{2}\right)$ and $3.1 \%$ underweight $\left(\mathrm{BMI}<18.5 \mathrm{~kg} / \mathrm{m}^{2}\right.$ ). The lower rates of overweight and obesity in this sample compared with the national average are almost certainly due to two factors: the predominance of students and the bias towards higher social class. However, although age was positively correlated with BMI ( $r$ 0.25; $P<0.001)$, with younger respondents having lower BMI, there was no association of higher BMI with lower social class in this sample $(r 0.06 ; P=0.402)$. 
Table 1. Description of obesity risk factors

\begin{tabular}{|c|c|}
\hline Factor & High scores indicate \\
\hline \multicolumn{2}{|l|}{ Dietary factors } \\
\hline Healthy eating & Less eating of healthy foodstuffs (this does not represent more eating of unhealthy foodstuffs) \\
\hline Amount eaten & Eating/choosing bigger portions, hard to stop eating a lot \\
\hline Convenience foods & More eating of fast/junk foods, less home cooking \\
\hline Emotional eating & More frequent eating when bored, anxious, not hungry \\
\hline Social influences on eating & Friends/family encouraging unhealthy eating \\
\hline \multicolumn{2}{|l|}{ Activity factors } \\
\hline Physical activity & Infrequent participation in physical activity (for example, sport, walking) \\
\hline Travel to work & More frequent driving to work, and/or not walking/cycling to work \\
\hline Mechanised transport & Using lifts not stairs, cars for short journeys \\
\hline Television watching & High amount of television watching/recreational computer use \\
\hline Social influences on physical activity & Friends/family encouraging not to be active \\
\hline \multicolumn{2}{|l|}{ Other factors } \\
\hline Dieting behaviour & More frequent and/or less successful weight-control behaviour \\
\hline Parental encouragement to be active & Less encouragement from both parents for child to be active when growing up \\
\hline Alcohol consumption & Higher amount of alcohol consumed (average week) \\
\hline Amount of sleep & Less sleep (based on usual hours per night) \\
\hline Mother's weight tendency & Mother being overweight and/or having frequent dieting behaviour \\
\hline Father's weight tendency & Father being overweight and/or having frequent dieting behaviour \\
\hline Early maturation & Heavier birth weight; taller at age 7 years \\
\hline
\end{tabular}

Males $\left(25.4(\mathrm{SD} 4.7) \mathrm{kg} / \mathrm{m}^{2}\right)$ had significantly higher BMI than females $\left(24.0(\mathrm{SD} 4.5) \mathrm{kg} / \mathrm{m}^{2}\right)(t(320)=2 \cdot 4 ; P=0 \cdot 015$; mean difference $1.4,95 \%$ CI $0.3,2.4)$. Male participants (mean age 33.0 (SD 14.6) years) in the current sample were also older than females (mean age 28.5 (SD 12.3) years) $(t(320)=2 \cdot 8 ; P=0.009$; mean difference $4 \cdot 5,95 \%$ CI $1 \cdot 1,7 \cdot 9)$, which may account for their higher BMI.

Because of the higher number of students leading to a skewed distribution on age, correlations on the risk factors with the age variable would not be appropriate. Instead a median split by age was carried out in order to create two groups for direct comparison; this resulted in a young age group ( $\leq 24$ years; $72 \%$ students) and an older age group ( $>24$ years; $8 \%$ students). Young participants had significantly lower BMI $\left(23.3(\mathrm{SD} 4 \cdot 3) \mathrm{kg} / \mathrm{m}^{2}\right)$ than the older age group $\left(25.5(\mathrm{SD} 4.6) \quad \mathrm{kg} / \mathrm{m}^{2}\right) \quad(t(320)=-4.5 ; \quad P<0.001 ;$ mean difference $-2 \cdot 2,95 \%$ CI $-3 \cdot 2,-1 \cdot 2)$. There was also an association between age group and sex with more males $(58.5 \%)$ in the older group and more females $(55.7 \%)$ in the young age group $\left(\chi^{2}(1)=5 \cdot 4 ; P=0.020\right)$.

\section{Relationship of the risk factor scores by age and sex}

As there were clear differences on BMI by both age and sex, as well as an association between age and sex, differences in scores on the obesity risk factors were examined (a) by age group based on a median split (i.e. $\leq 24$ years $v$. $>24$ years), (b) by sex and (c) between the four categories resulting from both age and sex split, i.e. young males ( $\leq 24$ years), older males ( $>24$ years), young females and older females. Independent $t$ tests were used to examine (a) and (b), and one-way ANOVA, with Scheffé for post hoc testing, was used to examine (c).

Young males ( $n$ 39) had a mean age of 19.4 (SD 1.5) years and a BMI of $23.4(\mathrm{SD} 4.4) \mathrm{kg} / \mathrm{m}^{2}$. Older males $(n$ 55) had a mean age of 42.7 (SD 11.6) years and a BMI of 26.7 $(\mathrm{SD} 4.5) \mathrm{kg} / \mathrm{m}^{2}$. Young females $(n$ 127) had a mean age of $19 \cdot 9$ (SD 2.0) years and a BMI of $23 \cdot 3(\mathrm{SD} 4 \cdot 3) \mathrm{kg} / \mathrm{m}^{2}$.
Older females ( $n$ 101) had a mean age of 39.4 (SD 11.1) years and a BMI of $24.9(\mathrm{SD} 4.5) \mathrm{kg} / \mathrm{m}^{2}$.

Table 2 shows the dietary factors split by age and sex. Males tended to report eating less healthily than females, although females were more likely to report eating for nonhunger reasons and more negative social influences on eating. Independent $t$ tests by sex confirmed that males were significantly less likely to eat healthy foods than females and that males reported eating higher amounts than females. In contrast, females were significantly more likely than males to report eating for reasons other than hunger (emotional eating, eating when bored), and greater negative social influences on eating.

Overall, younger participants reported less healthy dietary behaviours than those participants aged over 24 years; only amount eaten did not follow this pattern, but the difference on this factor was not significant (Table 2). The younger group were significantly less likely to eat healthy foods, more likely to eat for emotional reasons, more likely to report negative social influences on eating and more likely to eat convenience foods than their older counterparts.

One-way ANOVA between the four age/sex categories revealed significant differences between groups on all five dietary factors (Table 2). Post hoc Scheffé tests showed that older females reported significantly more eating of healthy food compared with young males and females. Older males also ate more healthy foods than young males. Both older and young females reported eating lesser amounts than older and young males, and older males and females ate fewer convenience foods than young males and females. Young females reported more frequent eating for emotional reasons than older males and females, and also more social influences on eating than older males.

Table 2 also shows the five activity factors split by age and sex. Independent $t$ tests by sex showed that there were no differences on any of the activity factors. However, any sex effects of travel to work are confounded by the relationship of this factor to age group (see below), as there are more older 
Table 2. Scores on BMI and dietary, activity and other factors by age and sex (Mean values and standard deviations)

\begin{tabular}{|c|c|c|c|c|c|c|c|c|c|c|c|c|c|c|c|c|c|c|c|}
\hline & \multicolumn{4}{|c|}{ Males } & \multicolumn{4}{|c|}{ Females } & & & & & & & & & & & \\
\hline & \multicolumn{2}{|c|}{$\begin{aligned} \leq & 24 \text { years } \\
& (n 39)\end{aligned}$} & \multicolumn{2}{|c|}{$\begin{array}{l}>24 \text { years } \\
\quad(n 55)\end{array}$} & \multicolumn{2}{|c|}{$\begin{aligned} \leq & 24 \text { years } \\
& (n 127)\end{aligned}$} & \multicolumn{2}{|c|}{$\begin{array}{c}>24 \text { years } \\
\quad(n \text { 101) }\end{array}$} & \multicolumn{3}{|c|}{$\begin{array}{l}\text { One-way ANOVA } \\
\text { by age and sext }\end{array}$} & \multicolumn{4}{|c|}{$\begin{array}{c}\text { Independent } t \text { tests } \\
\text { by sex (males } v \text {. females) }\end{array}$} & \multicolumn{4}{|c|}{$\begin{array}{l}\text { Independent } t \text { tests by age } \\
\text { group (young } v \text {. old) }\end{array}$} \\
\hline & Mean & SD & Mean & SD & Mean & SD & Mean & SD & $F(3,318)$ & $P$ & Post hoc & $t(320)$ & $P$ & $\begin{array}{c}\text { Mean } \\
\text { difference }\end{array}$ & $95 \% \mathrm{Cl}$ & $t(320)$ & $P$ & $\begin{array}{c}\text { Mean } \\
\text { difference }\end{array}$ & $95 \% \mathrm{Cl}$ \\
\hline \multicolumn{20}{|l|}{ Dietary factors } \\
\hline Healthy eating & 0.49 & 0.13 & 0.38 & 0.10 & 0.43 & 0.13 & 0.32 & 0.11 & 8.8 & $<0.001$ & $\begin{array}{l}1>2,4 \\
3>4\end{array}$ & $2 \cdot 6$ & 0.011 & 0.04 & $\begin{array}{l}0.01 \\
0.07\end{array}$ & $7 \cdot 7$ & $<0.001$ & 0.10 & $\begin{array}{l}0.08 \\
0.13\end{array}$ \\
\hline Emotional eating & 0.64 & 0.12 & 0.58 & 0.14 & 0.66 & 0.12 & 0.61 & 0.12 & $25 \cdot 2$ & $<0.001$ & $3>2,4$ & $-2 \cdot 3$ & 0.025 & -0.03 & $\begin{array}{l}-0.06 \\
-0.01\end{array}$ & 4.0 & $<0.001$ & 0.06 & $\begin{array}{l}0.03 \\
0.08\end{array}$ \\
\hline Social influences & 0.29 & 0.10 & 0.26 & 0.07 & 0.32 & 0.10 & 0.28 & 0.11 & $6 \cdot 1$ & $<0.001$ & $3>2$ & $-2 \cdot 8$ & 0.006 & -0.03 & $\begin{array}{c}-0.06 \\
-0.01\end{array}$ & 3.6 & $<0.001$ & 0.04 & $\begin{array}{l}0.02 \\
0.06\end{array}$ \\
\hline Amount eaten & 0.67 & 0.16 & 0.70 & 0.13 & 0.58 & 0.16 & 0.58 & 0.15 & $10 \cdot 1$ & $<0.001$ & $1,2>3,4$ & 5.4 & $<0.001$ & 0.10 & $0.06,0.14$ & $-1 \cdot 2$ & NS & -0.02 & $\begin{array}{r}-0.06 \\
0.01\end{array}$ \\
\hline Convenience food & 0.45 & 0.09 & 0.35 & 0.09 & 0.42 & 0.12 & 0.33 & 0.10 & 29.7 & $<0.001$ & $1,3>2,4$ & 1.1 & NS & 0.02 & $\begin{array}{r}-0.01 \\
0.04\end{array}$ & $7 \cdot 3$ & $<0.001$ & 0.09 & $\begin{array}{l}0.06 \\
0.11\end{array}$ \\
\hline \multicolumn{20}{|l|}{ Activity factors } \\
\hline Physical activity & 0.49 & 0.16 & 0.54 & 0.17 & 0.55 & 0.15 & 0.52 & 0.15 & $1 \cdot 4$ & NS & & -1.0 & NS & -0.02 & $\begin{array}{r}-0.06 \\
0.02\end{array}$ & 0.4 & NS & 0.01 & $\begin{array}{r}-0.03 \\
0.04\end{array}$ \\
\hline $\begin{array}{l}\text { Television watching } \\
\text { and computer use }\end{array}$ & 0.52 & 0.12 & 0.47 & 0.13 & 0.51 & 0.13 & 0.46 & 0.14 & $3 \cdot 2$ & 0.022 & & 0.05 & NS & 0.01 & $\begin{array}{r}-0.02 \\
0.04\end{array}$ & $3 \cdot 0$ & 0.003 & 0.04 & $\begin{array}{l}0.02 \\
0.07\end{array}$ \\
\hline $\begin{array}{l}\text { Travel to work } \\
\text { or college }\end{array}$ & 0.40 & 0.27 & 0.81 & 0.28 & 0.57 & 0.32 & 0.84 & 0.26 & $32 \cdot 2$ & $<0.001$ & $\begin{array}{l}1<2,3,4 \\
3<2,4\end{array}$ & $-1 \cdot 2$ & NS & -0.05 & $\begin{array}{r}-0.13 \\
0.03\end{array}$ & $-9 \cdot 2$ & $<0.001$ & -0.30 & $\begin{array}{l}-0.36 \\
-0.24\end{array}$ \\
\hline Social influences & 0.22 & 0.11 & 0.22 & 0.10 & 0.25 & 0.13 & 0.22 & 0.12 & $1 \cdot 2$ & NS & & $-1 \cdot 1$ & NS & -0.02 & $\begin{array}{r}-0.05 \\
0.01\end{array}$ & 1.5 & NS & 0.02 & $\begin{array}{r}-0.01 \\
0.05\end{array}$ \\
\hline Mechanised transport & 0.48 & 0.18 & 0.51 & 0.18 & 0.46 & $0 \cdot 17$ & 0.46 & 0.20 & $1 \cdot 0$ & NS & & 1.6 & NS & 0.04 & $\begin{array}{r}-0.01 \\
0.08\end{array}$ & -0.06 & NS & -0.01 & $\begin{array}{r}-0.05 \\
0.03\end{array}$ \\
\hline \multicolumn{20}{|l|}{ Other factors } \\
\hline Dieting behaviour & 0.43 & 0.18 & 0.52 & 0.20 & 0.54 & 0.19 & 0.55 & 0.22 & 3.7 & 0.012 & $1<3,4$ & -2.4 & 0.020 & -0.06 & $\begin{array}{l}-0.11 \\
-0.01\end{array}$ & -1.2 & NS & -0.03 & $\begin{array}{r}-0.07 \\
0.02\end{array}$ \\
\hline $\begin{array}{l}\text { Parental } \\
\text { encouragement } \\
\text { to be active }\end{array}$ & 0.52 & 0.22 & 0.55 & 0.24 & 0.53 & 0.22 & 0.54 & 0.25 & 0.2 & NS & & 0.2 & NS & 0.00 & $\begin{array}{r}-0.05 \\
0.06\end{array}$ & -0.8 & NS & -0.02 & $\begin{array}{r}-0.07 \\
0.03\end{array}$ \\
\hline Alcohol consumption & 0.58 & 0.21 & 0.60 & 0.25 & 0.50 & 0.19 & 0.54 & 0.25 & $2 \cdot 9$ & 0.034 & & $2 \cdot 6$ & 0.010 & 0.07 & $0.02,0.12$ & -1.7 & NS & -0.04 & $\begin{array}{r}-0.09 \\
0.01\end{array}$ \\
\hline Amount of sleep & 0.41 & 0.14 & 0.70 & 0.16 & 0.52 & 0.18 & 0.69 & 0.17 & $44 \cdot 2$ & $<0.001$ & $\begin{array}{l}1<2,3,4 \\
3<2,4\end{array}$ & -0.5 & NS & -0.01 & $\begin{array}{r}-0.06 \\
0.03\end{array}$ & $-10 \cdot 7$ & $<0.001$ & -0.20 & $\begin{array}{l}-0.24 \\
-0.16\end{array}$ \\
\hline $\begin{array}{l}\text { Mother's weight } \\
\text { tendency }\end{array}$ & 0.63 & 0.15 & 0.62 & 0.18 & 0.64 & 0.16 & 0.59 & 0.20 & 1.4 & NS & & 0.2 & NS & 0.00 & $\begin{array}{r}-0.04 \\
0.05\end{array}$ & 1.8 & NS & 0.04 & $\begin{array}{c}-0.003 \\
0.07\end{array}$ \\
\hline $\begin{array}{l}\text { Father's weight } \\
\text { tendency }\end{array}$ & 0.54 & 0.16 & 0.51 & 0.14 & 0.56 & 0.15 & 0.48 & 0.14 & 4.9 & 0.002 & $3>4$ & -0.1 & NS & -0.00 & $\begin{array}{r}-0.04 \\
0.03\end{array}$ & 3.8 & $<0.001$ & 0.06 & $\begin{array}{l}0.03 \\
0.09\end{array}$ \\
\hline Early maturation & 0.70 & 0.20 & 0.68 & 0.15 & 0.62 & 0.18 & 0.64 & 0.19 & $2 \cdot 4$ & 0.068 & & $2 \cdot 6$ & 0.009 & 0.06 & $\begin{array}{l}0.01 \\
0.10\end{array}$ & -0.5 & NS & -0.01 & $\begin{array}{r}-0.05 \\
0.03\end{array}$ \\
\hline Overall mean score & 0.50 & 0.05 & 0.53 & 0.05 & 0.51 & 0.06 & 0.51 & 0.06 & 2.8 & 0.040 & & $1 \cdot 0$ & NS & 0.01 & $\begin{array}{r}-0.01 \\
0.02\end{array}$ & $-1 \cdot 8$ & NS & -0.01 & $\begin{array}{r}-0.02 \\
0.001\end{array}$ \\
\hline
\end{tabular}

* Results of post hoc Scheffé tests were significantly different between the indicated groups $(P<0.05)$.

† Group 1, males $\leq 24$ years; group 2 , males $>24$ years; group 3, females $\leq 24$ years; group 4 , females $>24$ years. 
than young males in the sample, and more young than older females. Post hoc Scheffé tests (Table 2) of a one-way ANOVA by age and sex grouping did show that younger males had healthier behaviour with regard to travel to work compared with all other groups and younger females used healthier modes of travel to work than both older males and females.

Independent $t$ tests on the activity factors by age group showed that younger participants spent significantly more time watching television or DVDs or using a computer for recreation than the participants aged over 24 years, and that the younger age group had much healthier behaviour regarding travel to work (Table 2).

Table 2 also shows the seven remaining obesity risk factors ('other') split by age and sex. An overall mean score of all seventeen factors was also calculated, and differences on this variable by age/sex are shown in Table 2. A one-way ANOVA revealed a significant difference on the dieting behaviour factor, with young males reporting less (or more successful) dieting behaviour than older and young females. Amount of sleep was also significant, with young males reporting more sleep than the other three groups. Young females reported more sleep than older males and females and also significantly worse paternal weight behaviour (overweight and/or more dieting) than older females. There was an overall significant effect on alcohol consumption and on the mean score of all seventeen factors, with older males having the highest scores on these two measures, although post hoc Scheffé tests did not show any significant differences between individual groups.

Independent $t$ tests on the other factors by sex showed that females were more likely to participate in weight-control behaviour than males. Males reported more alcohol consumption than females and also had higher scores on the early maturation factor, that is, they were more likely to report being heavier at birth or taller than their peers at age 7 years (Table 2).

Younger participants were more likely to report parents as having more weight problems (higher parental weight and/or more weight-control behaviour), and this was significant for fathers (Table 2). This could be a reflection of the increasingly overweight population in recent years or that the young of today are more tuned in to weight issues generally. Younger participants reported much healthier sleep patterns (i.e. more sleep) than the older age group, although this could be a function of lifestyle or contextual factors in this age group.

\section{Differences on factor scores by weight category}

In order to examine whether any of the obesity risk factors could differentiate between the four weight categories, one-way ANOVA by weight category were conducted on each of the seventeen factors. The mean BMI scores for these weight categories were: underweight 17.8 (SD 0.5$) \mathrm{kg} / \mathrm{m}^{2}$, normal weight 21.9 (SD 1.6) kg/m ${ }^{2}$, overweight 27.0 (SD 1.3$) \mathrm{kg} / \mathrm{m}^{2}$ and obese 34.9 (SD 3.2$) \mathrm{kg} / \mathrm{m}^{2}$. Of the five dietary factors, three differentiated weight categories, i.e. emotional eating, amount eaten and social influences on eating (Table 3). Emotional eating scores tended to be higher as weight increased, and post hoc Scheffé tests showed that the obese were significantly more likely to report eating for non-hunger reasons than each of the other three weight categories. The overweight and obese were both significantly more likely to report eating higher amounts than the normal-weight group and the underweight reported eating lower amounts that each of the other three weight categories. There was an overall significant effect on social influences on eating, with the underweight having the highest score (i.e. most negative influences), and post hoc Scheffé tests showed the underweight had significantly higher scores than the overweight group.

Of the activity factors, three were able to differentiate between weight categories (Table 3). Post hoc Scheffé tests showed that the obese participated in significantly lower amounts of exercise and physical activity than each of the other three weight groups. The overweight were less likely to walk or cycle to work than the normal-weight category, and the obese were much more likely than the other three groups to use the car for short distances or use the lift rather than the stairs.

Of the other obesity risk factors, three were able to differentiate between weight categories (Table 3). Not surprisingly the dieting factor strongly differentiated between weight groups, with the underweight and normal-weight group participating in significantly less (or more successful) dieting behaviour than the overweight and obese groups. Sleep was also significant, with the underweight and normal-weight groups reporting having more sleep than the overweight and obese, although post hoc Scheffé tests only showed a significant difference between the normal and overweight categories (Table 3 ).

Both early maturation and parental encouragement to be active scores rose with weight but not sufficiently to reach significance (Table 3). Neither mother's nor father's weight tendency differentiated between weight categories. Finally, an overall mean of all factors showed a steady increase across weight categories and post hoc Scheffé tests showed it clearly differentiated the normal-weight and underweight from the overweight and obese weight categories (Table 3).

\section{Regression analysis}

A stepwise regression analysis of all seventeen factors plus age on log of BMI was performed (a) for the whole sample and (b) split into the four sex/age category groups reported above. A $\log$ transformation of BMI was carried out, as BMI itself was highly positively skewed, and the log transformation notably reduced the problems inherent in the skewed data, whilst not greatly having an impact on the results of the analysis. Stepwise regression was chosen to clarify the solution(s), as an Enter regression for the whole group only explained an additional $1.5 \%$ of the variance, indicating that the excluded factors did not account for much additional variance in BMI. The results of this regression are shown in Table 4.

The solution for the whole sample explained $39.2 \%$ of the variance in $\log (\mathrm{BMI})$ and nine factors reached significance: physical activity was the first factor selected, explaining $10.3 \%$ of the variance in BMI, dieting behaviour explained an additional $10.4 \%$, amount eaten $7.2 \%$, age $5.2 \%$, amount of sleep $1.3 \%$, healthy eating $1.6 \%$, early maturation $1.6 \%$, and alcohol consumption and social influences on eating $0.8 \%$ each. The last two factors were each related in a negative direction, i.e. lower alcohol consumption and fewer negative influences on eating were related to higher BMI. 
Table 3. Scores on dietary, activity and other factors by weight category (Mean values and standard deviations)

\begin{tabular}{|c|c|c|c|c|c|c|c|c|c|c|c|}
\hline & \multicolumn{2}{|c|}{$\begin{array}{l}\text { Underweight } \\
(\mathrm{BMl}<18.5 \\
\left.\mathrm{kg} / \mathrm{m}^{2}\right)(n 11)\end{array}$} & \multicolumn{2}{|c|}{$\begin{array}{c}\text { Normal }(\mathrm{BMI} \\
\left.18.5-24.9 \mathrm{~kg} / \mathrm{m}^{2}\right) \\
(n 194)\end{array}$} & \multicolumn{2}{|c|}{$\begin{array}{c}\text { Overweight (BMI } \\
\left.25 \cdot 0-29 \cdot 9 \mathrm{~kg} / \mathrm{m}^{2}\right) \\
(\text { n } 85)\end{array}$} & \multicolumn{2}{|c|}{$\begin{array}{c}\text { Obese } \\
(\mathrm{BMl} \geq 30 \cdot 0 \\
\left.\mathrm{kg} / \mathrm{m}^{2}\right)(n 32)\end{array}$} & \multicolumn{3}{|c|}{$\begin{array}{c}\text { One-way ANOVA by } \\
\text { weight category } \dagger\end{array}$} \\
\hline & Mean & SD & Mean & SD & Mean & SD & Mean & SD & $F(3,318)$ & $P$ & Scheffé post hoc test \\
\hline \multicolumn{12}{|l|}{ Dietary factors } \\
\hline Healthy eating & 0.43 & 0.13 & 0.39 & 0.13 & 0.40 & 0.12 & 0.42 & 0.17 & 0.8 & NS & \\
\hline Emotional eating & 0.56 & 0.11 & 0.62 & 0.12 & 0.63 & $0 \cdot 14$ & 0.71 & 0.14 & $5 \cdot 6$ & $<0.001$ & $1,2,3<4$ \\
\hline Social influences & 0.37 & 0.15 & 0.30 & 0.10 & 0.27 & 0.07 & 0.28 & 0.14 & $3 \cdot 8$ & 0.010 & $1>3$ \\
\hline Amount eaten & 0.44 & 0.16 & 0.59 & 0.15 & 0.65 & $0 \cdot 15$ & 0.68 & 0.18 & 9.9 & $<0.001$ & $1<2,3,42<3,4$ \\
\hline Convenience food & 0.39 & 0.15 & 0.39 & 0.11 & 0.39 & $0 \cdot 11$ & 0.37 & 0.12 & 0.3 & NS & \\
\hline \multicolumn{12}{|l|}{ Activity factors } \\
\hline Physical activity & 0.52 & 0.19 & 0.51 & 0.15 & 0.54 & $0 \cdot 16$ & 0.67 & 0.12 & 11.4 & $<0.001$ & $1,2,3<4$ \\
\hline Television watching and computer use & 0.45 & 0.13 & 0.48 & 0.13 & 0.49 & $0 \cdot 14$ & 0.50 & 0.14 & 0.6 & NS & \\
\hline Travel to work & 0.53 & 0.31 & 0.62 & 0.33 & 0.75 & 0.32 & 0.79 & 0.30 & 5.4 & 0.001 & $2<3$ \\
\hline Social influences & 0.30 & 0.22 & 0.23 & 0.12 & 0.23 & $0 \cdot 11$ & 0.23 & 0.12 & $1 \cdot 3$ & NS & \\
\hline Mechanised transport & 0.35 & 0.13 & 0.46 & $0 \cdot 18$ & 0.47 & 0.19 & 0.58 & 0.19 & $5 \cdot 6$ & 0.001 & $1,2,3<4$ \\
\hline \multicolumn{12}{|l|}{ Other factors } \\
\hline Dieting behaviour & 0.38 & 0.20 & 0.49 & 0.21 & 0.59 & $0 \cdot 17$ & 0.60 & 0.20 & $8 \cdot 7$ & $<0.001$ & $1,2<3,4$ \\
\hline Parental encouragement to be active & 0.42 & 0.22 & 0.52 & 0.22 & 0.56 & 0.26 & 0.59 & 0.25 & 1.8 & NS & \\
\hline Alcohol consumption & 0.48 & 0.18 & 0.54 & 0.22 & 0.58 & 0.22 & 0.47 & 0.26 & $2 \cdot 2$ & NS & \\
\hline Amount of sleep & 0.54 & 0.23 & 0.55 & 0.19 & 0.65 & $0 \cdot 16$ & 0.66 & 0.21 & $6 \cdot 6$ & $<0.001$ & $2<3$ \\
\hline Mother's weight tendency & 0.67 & 0.17 & 0.61 & 0.17 & 0.63 & $0 \cdot 18$ & 0.62 & 0.19 & $0 \cdot 6$ & NS & \\
\hline Father's weight tendency & 0.59 & 0.17 & 0.51 & 0.14 & 0.54 & 0.15 & 0.51 & 0.16 & 1.8 & NS & \\
\hline Early maturation & 0.62 & 0.16 & 0.63 & 0.18 & 0.65 & 0.19 & 0.71 & 0.19 & 1.9 & NS & \\
\hline Overall mean score & 0.47 & 0.04 & 0.50 & 0.05 & 0.53 & 0.05 & 0.55 & 0.06 & $16 \cdot 7$ & $<0.001$ & $1,2<3,4$ \\
\hline
\end{tabular}

Da
0
0
0
0
0
0
0
0
0
0
0
0
0
0
0
0
0
0
0
0
0
0
0
0
0
0
0
0
0
0

${ }^{*}$ Results of post hoc Scheffé tests were significantly different between the indicated groups $(P<0.05)$.

† Group 1, underweight; group 2, normal weight; group 3,overweight; group 4, obese. 
Table 4. Stepwise regression analysis of the seventeen factors plus age on $\log (\mathrm{BMI})$

\begin{tabular}{|c|c|c|c|c|c|c|c|c|c|c|}
\hline & \multicolumn{2}{|c|}{$\begin{array}{l}\text { Whole sample } \\
\qquad(n \text { 322) }\end{array}$} & \multicolumn{2}{|c|}{$\begin{array}{l}\text { Young males } \\
(n 39)\end{array}$} & \multicolumn{2}{|c|}{$\begin{array}{l}\text { Older males } \\
\quad(n 55)\end{array}$} & \multicolumn{2}{|c|}{$\begin{array}{l}\text { Young females } \\
\quad(n 127)\end{array}$} & \multicolumn{2}{|c|}{$\begin{array}{l}\text { Older females } \\
\quad(n \text { 101) }\end{array}$} \\
\hline & $\beta$ & $P$ & $\beta$ & $P$ & $\beta$ & $P$ & $\beta$ & $P$ & $\beta$ & $P$ \\
\hline ANOVA (all significant at $P<0.001$ ) & \multicolumn{2}{|c|}{$F(8,313)=22 \cdot 4$} & \multicolumn{2}{|c|}{$F(4,38)=10 \cdot 5$} & \multicolumn{2}{|c|}{$F(3,51)=9.5$} & \multicolumn{2}{|c|}{$F(4,122)=13 \cdot 0$} & \multicolumn{2}{|c|}{$F(5,95)=15 \cdot 6$} \\
\hline Multiple $r$ & \multicolumn{2}{|c|}{0.626} & \multicolumn{2}{|c|}{0.744} & \multicolumn{2}{|c|}{0.600} & \multicolumn{2}{|c|}{0.570} & \multicolumn{2}{|c|}{0.682} \\
\hline Adjusted $r^{2}$ & \multirow{2}{*}{\multicolumn{2}{|c|}{$\begin{array}{l}0.375 \\
39.2\end{array}$}} & \multicolumn{2}{|c|}{0.501} & \multicolumn{2}{|c|}{0.322} & \multicolumn{2}{|c|}{0.297} & \multicolumn{2}{|c|}{0.438} \\
\hline Amount of variance explained $\left(r^{2}\right)(\%)$ & & & $55 \cdot$ & & \multicolumn{2}{|c|}{$36 \cdot 0$} & \multirow{2}{*}{\multicolumn{2}{|c|}{$32 \cdot 5$}} & \multirow{2}{*}{\multicolumn{2}{|c|}{$46 \cdot 6$}} \\
\hline \multicolumn{7}{|l|}{ Significant factors } & & & & \\
\hline Physical activity & 0.304 & $<0.001$ & & & 0.278 & 0.017 & 0.452 & $<0.001$ & 0.343 & $<0.001$ \\
\hline Dieting behaviour & 0.283 & $<0.001$ & 0.448 & $<0.001$ & 0.298 & 0.019 & 0.252 & 0.001 & 0.348 & $<0.001$ \\
\hline Amount eaten & 0.252 & $<0.001$ & & & & & 0.243 & 0.003 & 0.234 & 0.003 \\
\hline Age & 0.215 & $<0.001$ & & & & & 0.164 & 0.035 & & \\
\hline Healthy eating & 0.180 & 0.001 & 0.333 & 0.008 & & & & & & \\
\hline Amount of sleep & 0.149 & 0.007 & & & 0.345 & 0.007 & & & & \\
\hline Early maturation & $0 \cdot 124$ & 0.007 & 0.429 & 0.001 & & & & & & \\
\hline Alcohol consumption & -0.100 & 0.034 & & & & & -0.234 & 0.021 & & \\
\hline Social influences on eating & -0.094 & 0.042 & -0.358 & 0.005 & & & & & & \\
\hline Emotional eating & & & & & & & & & 0.337 & $<0.001$ \\
\hline Mother's weight tendency & & & & & & & & & -0.270 & 0.001 \\
\hline
\end{tabular}

For the young males, only four factors reached significance, and the solution explained $55.4 \%$ of the variance in $\log (\mathrm{BMI})$ : dieting behaviour explained $21.8 \%$ of the variance, healthy eating an additional $10.3 \%$, early maturation $12.4 \%$ and social influences on eating $10.9 \%$. For older males, the solution explained $36.0 \%$ of the variance with only three factors reaching significance: dieting behaviour explaining $20.2 \%$, amount of sleep $8.1 \%$ and physical activity $7.7 \%$. For young females, the solution explained $32.5 \%$ of the variance, with five factors reaching significance: physical activity explained $15.6 \%$ of the variance, amount eaten a further $6.9 \%$, dieting behaviour $4.2 \%$, alcohol consumption $3.2 \%$ and age $2.6 \%$. As with the whole sample, alcohol consumption was associated in a negative direction with BMI. Finally for older females, $46.6 \%$ of the variance in $\log (\mathrm{BMI})$ was explained, with five factors reaching significance, two of which were not significant for the whole sample: emotional eating was the most important factor explaining $20.3 \%$ of the variance in BMI, dieting behaviour explained an additional $7.7 \%$, physical activity $8.3 \%$, mother's weight tendency $5.2 \%$ and amount eaten $5 \cdot 1 \%$. Mother's weight tendency was associated in a negative direction, i.e. those with higher BMI reported their mothers as being of lower weight and/or exhibiting less dieting behaviour.

\section{Discussion}

This previously developed comprehensive measure of obesity risk resulted in seventeen factors which are examined in the present report in relation to age, sex, weight category and BMI. Of the eating factors, both emotional eating and amount eaten clearly differentiated the weight categories, with the obese reporting more emotional eating than any other group, with both the overweight and obese reporting eating higher amounts than the normal-weight group, and the underweight reporting eating less than all other groups. Interestingly, in this sample, there were no differences between weight groups with respect to either the eating of healthy foods or the eating of convenience foods, which is representative of unhealthy eating patterns. Further, although social influences on eating differed between weight categories, this was in an unexpected direction, with the underweight having the highest scores, and the overweight and obese the lowest.

It is now suggested that the abundance of easily obtainable, energy-dense food in our society, making it easy to follow our innate impulse to store food in times of plenty as protection against future famine, is fuelling the obesity crisis ${ }^{(1)}$. Our finding that the obese reported much more eating for non-hungerrelated reasons (anxiety, depression, boredom) than the other three groups suggests that they may be more at risk from this abundance, and that behavioural interventions at an individual level will need to address underlying psychological motivations for eating, as well as actual dietary behaviours.

It is well accepted that social desirability may play a part in the reporting of eating behaviours among the overweight, where under-reporting is thought to be common ${ }^{(30)}$, so it is interesting to note that the overweight and obese did report higher amounts of food consumption in the present study. Questionnaire items which load on this factor include 'I tend to eat everything put in front of me' and 'I feel I've eaten or drunk more than I should', which may be less transparent about what they are measuring than the item 'When ordering food or drink items I choose the largest size' (which also loads on this factor), and hence led to more honest responses. Additionally it is possible that the overweight simply perceive that they eat large amounts, as they are aware that they have a weight problem. Nonetheless the underweight, who might be supposed to be unworried about reporting eating a lot, also reported much lower food consumption that the other three groups and normal-weight participants reported eating less than both the overweight and obese groups. The results suggest that those of low or normal weight may be better able to self-regulate food intake to energy expenditure than the overweight and/or obese who may be more susceptible to external cues.

The fact that healthy and unhealthy eating patterns were not able to distinguish weight groups in this sample may be due to the relatively healthy eating reported by this high socioeconomic group, and therefore this would need to be examined 
in a much wider demographic. Nonetheless, if healthy eating is to be shown to be less important than psychological influences on food consumption and amount eaten, this has notable implications for the many current initiatives promoting healthy eating as a means of tackling the obesity crisis, notwithstanding the need to eat healthily in the wider health context. If individuals simply eat too much, and are motivated by non-hunger-related reasons, the type of food eaten may be of less importance than is perhaps generally thought.

Active participation in physical activity and exercise, mode of travel to work and use of mechanised transport were all able to differentiate weight categories, especially of the obese from the other weight groups. As expected, activity levels generally seem to be an important factor in determining BMI. Again, with regard to participation in physical activity, psychological motivations may be important, and activity levels in the already overweight are likely to be reduced, due to perceived barriers such as embarrassment as well as physical difficulties in taking exercise. Higher scores on amount of sleep (i.e. less sleep) and the overall mean score of all factors were also observed in the overweight and obese $v$. the underweight and normal-weight groups. Short sleep has been associated with increased weight in children, but the results in adults are more mixed ${ }^{(32)}$. In the current sample, the association of lower amounts of sleep with higher BMI may be explained by the association of both with older age, as the young age group reported better (i.e. more) sleep. As many of this group were students, these healthier sleep patterns may simply reflect increased opportunities to sleep longer, though it could also be a sign of more sleep difficulties in older adults. Nonetheless, our findings suggest that further exploration of this area is required, especially as sleep is generally overlooked as a risk factor in obesity studies.

Not surprisingly, the underweight reported much less dieting behaviour than the other three weight groups, and the normal weight also reported less dieting than the overweight and obese. Unfortunately, although the questionnaire has individual items relating to both past and present weight-control behaviour, all of these items loaded on just one factor, which makes it hard to determine whether past behaviour, such as yo-yo dieting, is a determinant of BMI in the present study or whether the increased dieting behaviour in the overweight groups is a response to their weight gain.

Regression analysis for the whole group, which included all seventeen factors plus age as predictor variables, predicted two-fifths of the variance in BMI, with physical activity, dieting behaviour, amount eaten and age being the strongest predictors. Quite different patterns in the regression analysis emerged by age/sex group, with the greatest differences being between the young males and the other three groups. For young males, dieting behaviour, healthy eating and early maturation were the strongest predictors, with social influences on eating also being related to BMI, but in a negative direction, i.e. the fewer reported influences, the higher the BMI. It is possible that this may be a social desirability response.

Physical activity participation and amount eaten did not reach significance for young males, although it should be noted that this group had the highest levels of reported physical activity and the second highest scores on amount eaten overall. Sleep only reached significance as a predictor for older males, alongside physical activity and dieting behaviour. Physical activity, dieting behaviour and amount eaten were significant predictors for both young and older females. Emotional eating only reached significance for older females.

Overall, males reported eating more than females, perhaps explaining why amount eaten was a more important predictor of BMI for females than males. For older males, more dieting behaviour was associated with higher amounts eaten, which supports the notion of yo-yo dieting, where weight loss is followed by increased weight gain. In young males, it seems likely that the higher amounts they reported eating still match their overall energy expenditure, but this may become a problem as they age and their activity levels decrease. Interestingly, less eating of healthy foods was associated with higher BMI in this group only, and this may need to be a target area for young males, who also scored markedly worse on this factor than the other groups.

These different patterns indicate that the relationship between the various risk factors and obesity may be even more complex than imagined, and may differ by both sex and age group. Many studies do not make these distinctions, so we have shown that it is important for future research to take this into consideration, even to the extent that different interventions may need to be targeted at different groups.

An important finding of the regression analysis is that, when a comprehensive range of factors was included simultaneously, two of the strongest predictors of higher BMI were lack of physical activity participation (energy out) and higher amounts eaten (energy in). If these results replicate in other groups, then this suggests that a key approach in solving the obesity problem could be to provide individuals with strategies required to help them regulate this basic energy equation, rather than necessarily concentrating on the types of food eaten, or encouraging participation in specific forms of regular exercise, which may be difficult to sustain. Interventions would particularly include examining psychological influences on eating, and motivations for physical activity participation, as well as providing effective means of monitoring weight, to ensure that a positive energy balance is not allowed to continue over a prolonged period of time. Such approaches could be useful in preventing individuals becoming overweight in the first place, as well as helping maintain weight loss and preventing further weight gain in the already overweight.

There were also important findings regarding different patterns by age in the present study, particularly with respect to eating behaviour. Young participants consistently reported less healthy eating, more emotional eating and more negative influences on eating than their older counterparts, although the effect of this was offset in the present study by their increased general activity levels, which is likely to explain their lower BMI. However, as we may expect that activity levels decrease with age, if the potentially harmful eating patterns of this young group are not addressed, they may well end up with greater weight problems than the previous generation, who here reported much healthier eating. If this pattern of poorer eating habits is replicated in other young samples, then this could have serious implications for the predicted rise in obesity levels. 


\section{Limitations}

We used a self-report questionnaire, which is open to possible reporting biases; however, the fact that the overweight did report eating larger amounts suggests that some of these expected biases have been negated by careful choice of item wording. Weight and height were also self-reported in the present study, but previously reported validation of the resulting BMI scores/weight categories with items relating to clothes size $^{(24)}$ as well as high correlations with both participants' and their families' views of their being overweight and/or needing to lose weight ${ }^{(24)}$ suggested fairly accurate reporting.

This self-selected sample was biased towards higher socioeconomic groups, younger age group, and also towards lower BMI, meaning that the results may not generalise to the wider population and need to be replicated in a wider demographic sample. Also the age/sex split resulted in uneven numbers between groups, meaning that the reported differences in the regression analysis may also have affected the results for the whole sample. In addition, reported levels of obesity in the present study were higher in males than females, counter to the national trend for Scotland ${ }^{(33)}$, and this bias may also have affected the findings. Finally, the study was crosssectional, and so a longitudinal study is needed to see to what degree these obesity risk factors can predict weight gain and/or future BMI. There was an added confound of the dieting behaviour factor, where items relating to both past and present behaviour loaded on this factor. This will need to be addressed in future versions of the questionnaire.

\section{Summary}

We have developed an easy-to-use self-report questionnaire, which has allowed us to examine the relative importance of a wide range of obesity risk factors in determining BMI. Physical activity and amount eaten, alongside current and past dieting behaviour, and to a lesser extent age, were the most important predictors of BMI. Significant predictors differed by age group and sex, with stepwise regression analysis predicting between 25 and $55 \%$ of the variance in BMI. Young participants reported much less healthy eating behaviour than the older age group, which has important implications for future obesity levels, as activity is expected to decline with age.

\section{Acknowledgements}

This research received no specific grant from any funding agency in the public, commercial or not-for-profit sectors.

J. A. C. and V. S. designed the study, devised the questionnaire and compiled the manuscript. J. A. C. also collected and analysed the data.

There are no conflicts of interest.

\section{References}

1. Jebb SA, Kopelman P \& Butland B (2007) Executive summary: Foresight Tackling Obesity: Future Choices Project. Obes Rev 8, Suppl. 1, vi-ix.

2. Flegal KM, Caroll MD, Ogden CL, et al. (2002) Prevalence and trends in obesity among US adults, 1990-2000. JAMA $\mathbf{2 8 8}$, $1723-1727$.
3. Monteiro CA, Moura EC, Conde WL, et al. (2004) Socioeconomic status and obesity in adult populations of developing countries: a review. Bull World Health Organ 82, 940-946.

4. Patterson RE, Frank LL, Kristal AR, et al. (2004) A comprehensive examination of health conditions associated with obesity in older adults. Am J Prev Med 27, 385-390.

5. Guh DP, Zhang W, Bansback N, et al. (2009) The incidence of co-morbidities related to obesity and overweight: a systematic review and meta-analysis. BMC Public Health 9, 88.

6. Whitaker RC, Wright JA, Pepe MS, et al. (1997) Predicting obesity in young adulthood from childhood and parental obesity. $N$ Engl J Med 337, 869-873.

7. Whitaker RC \& Dietz WH (1998) The role of the environment in the development of obesity. J Pediatr 132, 768-776.

8. Foresight (2007) Foresight Tackling Obesities: Future Choices Project. http://www.foresight.gov.uk (accessed September 2009).

9. Hill JO, Melanson EL \& Wyatt HT (2002) Dietary fat intake and regulation of energy: implications for obesity. J Nutr 130, S284-S288.

10. Lobstein T (2004) Obesity in children and young people: a crisis in public health. Obes Rev 5, Suppl. 1, 4-85.

11. Ludwig DS, Peterson KE \& Gortmaker SL (2001) Relation between consumption of sugar-sweetened drinks and childhood obesity: a prospective observational analysis. Lancet 357, 505-508.

12. Prentice AM \& Jebb SA (2003) Fast foods, energy density and obesity: a possible mechanistic link. Obes Rev 4, 187-194.

13. Rolls BJ, Morris EL \& Roe LS (2002) Portion size of food affects energy intake in normal-weight and overweight men and women. Am J Clin Nutr 76, 1207-1213.

14. Tuomisto T, Tuomisto MT, Hetherington M, et al. (1998) Reasons for initiation and cessation of eating in obese men and women and the affective consequences of eating in everyday situations. Appetite 30, 211-222.

15. Ma Y, Bertone ER, Stanek EJ III, et al. (2003) Association between eating patterns and obesity in a free-living US adult population. Am J Epidemiol 158, 85-92.

16. French SA, Jeffrey RW, Forster JL, et al. (1994) Predictors of weight change over two years among a population of working adults: The Healthy Worker Project. Int J Obes 18, 145-154.

17. Gortmaker SL, Must A, Sobol AM, et al. (1996) Television viewing as a cause of increasing obesity among children in the United States, 1986-1990. Arch Pediatr Adolesc Med 150, 356-362.

18. Jebb SA \& Moore MS (1999) Contribution of a sedentary lifestyle and inactivity to the etiology of overweight and obesity: current evidence and research issues. Med Sci Sports Exerc 31, Suppl. 11, S534-S541.

19. Prentice AM \& Jebb SA (1995) Obesity in Britain: gluttony or sloth? Br Med J 311, 437-439.

20. Von Kries R, Kolezo B, Sauerweld T, et al. (1999) Breast feeding and obesity: cross sectional study. BMJ 319, 147-150.

21. Hasler G, Buysse DJ, Klaghofer R, et al. (2004) The association between short sleep duration and obesity in young adults: a 13-year prospective study. Sleep 27, 661-666.

22. Newmark-Sztainer D, Wall M, Guo J, et al. (2006) Obesity, disordered eating, and eating disorders in a longitudinal study of adolescents: how do dieters fare 5 years later? J Am Diet Assoc 106, 559-568.

23. Leibman M, Pelican S, Moore SA, et al. (2005) Dietary intake-, eating behaviour- and physical activity-related determinants of high body mass index in the 2003 Wellness in the Rockies cross-sectional study. Nutr Res 26, 111-117.

24. Chambers JA \& Swanson V (2006) A health assessment tool for multiple risk factors for obesity: results from a pilot study with UK adults. Patient Educ Counsel 62, 79-88. 
25. Chambers JA \& Swanson V (2008) A health assessment tool for multiple risk factors for obesity: psychometric testing and age differences in UK adults. Obesity Facts 1, 227-236.

26. Office of Population and Census Surveys (OPCS) (1991) Classification of Occupations. London: HM Stationery Office.

27. Wardle J, Guthrie CA, Sanderson S, et al. (2001) Development of the Children's Eating Behaviour questionnaire. J Child Psychol Psychiatry 42, 963-970.

28. World Health Organization (2000) Health and Health Behaviour Among Young People. WHO Policy Series: Health Policy for Children and Adolescents no. 1. Geneva: WHO.
29. Flesch RF (1948) A new readability yardstick. J Appl Psychol 32, 221-233.

30. Heitmann BL \& Lissner L (1995) Dietary underreporting by obese individuals - is it specific or non-specific? BMJ 311, 986-989.

31. World Health Organization (2000) Obesity: Preventing and Managing the Global Epidemic. Report of a WHO Consultation. WHO Technical Report Series no. 894. Geneva: WHO.

32. Patel SR \& Hu FB (2008) Short sleep duration and weight gain: a systematic review. Obesity 16, 643-653.

33. Scottish Government (2008) The Scottish Health Survey 2008. Edinburgh: Blackwell. 